\title{
Antoine Compagnon, El demonio de la teoría. Literatura y sentido común.
}

\author{
Barcelona, Acantilado, 2015, traducción de Manuel Arranz, 344 páginas.
}

\section{Cristian Vaccarini}

Dos voces distintas parecen hablarnos cada vez que leemos literatura: la de un daimon que, como el socrático, nos indica desde dónde debemos leer y cómo hacerlo, y la de nuestros saberes no teorizados, que Compagnon denomina "sentido común” o "prejuicios". Sobre la base de la confluencia y la rivalidad de estas dos voces, muchas veces antitéticas en extremo, Compagnon articula el eje conceptual de su libro. A partir del estado de la teoría literaria francesa durante el siglo XX, El demonio de la teoría se dedica a estudiar "el perpetuo antagonismo entre la teoría y el sentido común” (p. 306), pasando revista a los continuos esfuerzos de la primera por organizar los estudios literarios y a las no menos continuas resistencias del segundo.

A fines de siglo (la edición original de El démon de la théorie es de 1998), Compagnon lamenta que la teoría francesa no haya encontrado los herederos de los nombres rutilantes de las décadas del sesenta y del setenta. No sólo la teoría parece haber perdido fuerza como objeto de estudio: la literatura también compartiría esa suerte. Ante este panorama, el autor propone el escepticismo y el cuestionamiento como puntos de partida epistemológicos para leer las teorías literarias: en vez de la duda cartesiana de su célebre compatriota, la duda hiperbólica.

Compagnon reivindica el carácter polémico de las teorías literarias, que la academia amortigua, incluso aplana al convertirlas en método. De este modo, su mirada se enfoca en las rivalidades y en los conflictos que las diversas teorías sobre la literatura mantienen entre sí. El epígrafe del libro (tomado del poema 49 de Los pequeños poemas en prosa o El spleen de París de Baudelaire) lo anuncia: “Aquel pobre Sócrates no tenía más que un demonio negador; el mío es un gran afirmador, el mío es un demonio de acción, un demonio de combate”. 
Nuestro autor reproduce en la organización y escritura de los capítulos esa lógica del disenso y la pugna que caracteriza al campo. A la manera de un retórico o de un jurista, presenta posiciones diversas y antitéticas que pretenden explicar cada categoría; reseña los argumentos a favor y en contra de cada posición, y finalmente trata de encontrar una tercera postura, sin perder en el camino ni rigor descriptivo ni alcance explicativo. De este modo, en cada uno de los capítulos el autor procede por dicotomías y llega (o parece llegar) a aporías que no inclinan la balanza ni hacia la teoría ni hacia el sentido común.

Cada capítulo del libro se dedica a una categoría clave y persistente de los estudios literarios: la literatura, el autor, el referente, el lector, el lenguaje, la historia y el valor. Las primeras cinco categorías se corresponden con sendas preguntas, desde la inicial “¿Qué es la literatura?” hasta “¿Qué relación hay entre la literatura y el lenguaje?”. Las dos categorías restantes, ubicadas en un nivel algo distinto, también se traducen en preguntas. Las siete categorías se organizan en un sistema pues cada una de las preguntas remite a las otras: al responder una de determinada manera, quedan limitadas las opciones para responder las demás.

El primer capítulo, "La literatura”, recorre su objeto a través de las nociones de dimensión y función de la literatura (¿Qué es la literatura? ¿Para qué sirve?), y de las de forma del contenido y forma de la expresión (a partir de las distinciones de Hjelmslev, se introducen las categorías de ficción y de cierto uso del lenguaje como criterios definidores). Se despliegan en este capítulo las posturas del fundacional Aristóteles, Kant, el formalismo ruso, Jakobson y Genette. También, una interesante reflexión sobre las funciones que puede cumplir la literatura: como fuerza subversiva del orden social imperante o como su sostén.

"El autor" ("el punto más controvertido en los estudios literarios”, p. 52) se detiene en la filología y la hermenéutica, y en las categorías de coherencia, premeditación, sentido y significado, en un arco que va desde el reconocimiento de intenciones hasta la postestructuralista "muerte del autor", de Gadamer a Barthes (uno de los autores más considerados por Compagnon). El capítulo le dedica un tramo especial a la disputa entre Jakobson y Lévi-Strauss por un lado y Rifaterre por el otro, a propósito del análisis de "Los gatos" de Baudelaire realizado por aquellos.

"El mundo" se ocupa de las respuestas que las teorías literarias le han dado a la compleja pregunta “¿De qué habla la literatura?”. Compagnon pivotea sobre las categorías de mimesis y autorreferencialidad, y analiza las versiones de mimesis propuestas por Platón (de la que partió originalmente el trabajo de Auerbach) y Aristóteles, punto en el cual reaparece la doble función de la literatura como represiva o como subversiva. Analiza también el dialogismo de Bajtín, la posterior intertextualidad de Kristeva y las tesis de Blanchot. El capítulo se extiende en una fundamentada crítica al Barthes antirreferencial de $S$ / $Z$ y revisa las posturas de Frye y de Ricoeur, para terminar con la categoría de mundos ficcionales. "El mundo” es quizá el capítulo en el que más claramente se nota que las teorías que parten de la lingüística saussureana no gozan del aprecio de Compagnon.

En "El lector" Compagnon afirma que, antes que por los lectores reales, las teorías se han preocupado por el lector ideal (p. 169-170). El capítulo revisa las reflexiones de Proust y Mallarmé sobre el tema y diversas teorías de la recepción, especialmente las de Ingarden, Iser y Fish. Se ocupa también de las historias de la lectura y de la edición, como los trabajos de Chartier en la década de los ochenta. Este capítulo reviste un interés adicional: el destino del lector "en la teoría literaria es ejemplar” (p. 194); después de haber sido un componente de la literatura marginado o directamente no tenido en cuenta, llegó a ocupar el centro de la escena y a desplazar a los demás componentes. "Parece que le sea imposible a la teoría preservar el equilibrio entre los elementos de la literatura” (p. 195) es la conclusión que, al pasar, deja caer Compagnon y que podría ser el punto de partida de otro libro sobre las teorías literarias.

Por su parte, "El estilo" ("el concepto fundamental de la historia del arte del siglo XIX, en todos los sentidos del término, y en todos los niveles estéticos”, p. 204) retoma la cuestión del lenguaje y se dedica a indagar en 
las problemáticas relaciones entre el texto literario y la lengua. Compagnon trata diversas definiciones de estilo, toma las posturas del Barthes de El grado cero de la escritura y de Spitzer, y recorre los vínculos entre la lengua y la norma, la transgresión, el contexto y el pensamiento. Un aporte desde la filosofía de Goodman parece resolver el problema.

Los dos últimos capítulos difieren en un aspecto de los anteriores. La historia literaria y el valor literario son nociones que responden a los vínculos de los textos entre sí; estos capítulos, entonces, cambian la perspectiva: el punto de mira se convierte en comparativo. Así, "La historia" (término ambiguo que responde tanto a la dinámica de la literatura como a su contexto) se ocupa de la historia literaria, la social y la de las ideas literarias, y de la categoría de evolución. En este capítulo Compagnon introduce la crítica, "cuya separación estanca” con la historia literaria "debe ser denunciada como una trampa (eso es lo que ha hecho la teoría), como todas las polaridades que minan los estudios literarios, pero no para renunciar tanto a una como a la otra. Al contrario, para manejar una y otra con conocimiento de causa” (p. 243). Este es uno de los numerosos pasajes en los que el autor explicita el eje que articula el libro. Completan el capítulo una revisión del "horizonte de expectativas" de Jauss y de los estudios culturales, y el paso por la historia del libro y por la sociología de Bourdieu.

Por su parte, "El valor" se dedica de lleno a la crítica. Compagnon analiza diversos criterios que definen lo bello y atiende al itinerario histórico de categorías como la de clásico. Respecto de esta, dos posturas privilegian su atención: la de Sainte-Beuve en el siglo XIX y la de Gadamer en el XX. Compagnon revisa además los argumentos de la perduración en el tiempo y la extensión fuera de las fronteras nacionales como criterios de valoración. Con las nociones de gusto, canon y tradición el autor finaliza su recorrido.

Llegados a este punto, surge legítima la pregunta sobre cómo lee Compagnon las teorías literarias. En su “Conclusión. La aventura teórica”, afirma que las lee como una novela, según la técnica de Pierre Menard, es decir la "del anacronismo deliberado y las atribuciones erróneas”. La respuesta no resulta del todo convincente ya que parece restarle consistencia al trabajo previo, aunque en seguida Compagnon nos advierte sobre el previsible riesgo de la relativización indiscriminada, pues "la ambición teórica [...] debe ser tomada en serio y valorada según su propio proyecto" (p. 308). Pareciera, entonces, que "leerlas como una novela” obedece más a la atención que el autor coloca en sus rivalidades y conflictos antes que en una operación que les quitara a las teorías su estatuto conceptual, su contexto histórico o su raigambre en la filosofía, la historia o la lingüística.

El libro merecía una tarea de edición más cuidadosa, que hubiera evitado varias erratas y, sobre todo, la irritante y frecuente aparición de "literalidad" en vez de "literaturidad", especialmente en el capítulo "Literatura". Tampoco queda muy claro, en los tramos iniciales, de qué dicotomía de Platón se nos habla. Ahondando en la lectura, podrían objetarse algunos de los postulados de Compagnon, como el de que todas las teorías nacen insurreccionales, o alguna de las conclusiones del capítulo "La literatura". Y llaman la atención algunas ausencias, por ejemplo las de Mukařovskýy Lotman entre los nombres propios, y la de la williamsiana tradición selectiva entre las categorías. Afanarse en objeciones y ausencias podría provocar, desde ya, el efecto beligerante buscado por el autor. No es el objetivo ahora y sería algo injusto. El trabajo de Compagnon es un muy valioso recorrido por las principales categorías tratadas en las teorías sobre la literatura, que se escapa con éxito de quedar atenazado por una teoría en particular o por las demandas del sentido común.

También en 2015 aparecieron las indispensables Clases 1985. Algunos problemas de teoría literaria, de Josefina Ludmer, que ya habían considerado que la teoría literaria es un campo de debates y de polémicas. En este sentido, la edición del libro de Compagnonen español viene a sumarse a una bienvenida actualización de la bibliografía publicada en nuestro país sobre los estudios literarios. 